EESTI NSV TEADUSTE AKADEEMIA TOIMETISED. X KOIDE

FOOSIKALIS-MATEMAATILISTE JA TEHNILISTE TEADUSTE SEERIA. 1961, NR. 2

ИЗВЕСТИЯ АКАДЕМИИ НАУК ЭСТОНСКОИ ССР. ТОМ Х

СЕРИЯ ФИЗИКО-МАТЕМАТИЧЕСКИХ И ТЕХНИЧЕСКИХ НАУК. 1961, № 2

\title{
К ВОПРОСУ О ДОПУСТИМЫХ КОЛЕБАНИЯХ СОДЕРЖАНИЯ СаО И МgO В КЛИНКЕРЕ ПЛАВЛЕНОГО ПОРТЛАНД-ЦЕМЕНТА
}

\author{
М. КИилЕР, \\ кандидат технических наук
}

Работы, проведенные в 1958-1959 гг. в ИСС.М АН ЭСС.Р $\left[{ }^{3}\right]$ и в институте «Гипроцемент», показали принципиальную возможность получения плавленого портландцемента из минеральной части горючего сланца, добытого из слоев от А до $\mathrm{H}$ (или от A до F) вместе со слоями известняка. Было выяснено также, что минералогический состав и механическая прочность цемента находятся в определенной зависимости от химического состава плавленого клинкера.

Колебания химического состава минеральной части сланца связаны, в основном, с различным содержанием известняка в вырабатываемой горной массе, а также со степенью его доломитизации. В связи с этим при плавлении минеральной части горючего сланца получаются цементы с различным коэффициентом насыщения и разным содержанием окиси магния при постоянном силикатном и алюминатном модулях. Цель настоящей работы * заключалась в установлении пределов, в которых может колебаться содержание $\mathrm{CaO}$ в сланцезольном расплаве для получения из него цемента, не претерпевающего недопустимых объемных изменений из-за высокого содержания свободной извести и обладающего хорошей механической прочностью. Кроме того, рассматривалась возможность получения качественного портланд-цемента из шихты, содержащей повышенное количество окиси магния.

Исходным материалом служили сланцы месторождения «Вийвиконна». На их основе было составлено шесть шихт с различным содержанием окиси кальция. Плавление шихт проводилось в пламени ацетиленово-кислородной горелки. Капли расплава охлаждались как в воде, так и на воздухе (падали на керамическую подставку). Полученные клинкеры имели коэффициент насыщения от 0,7 до 1,1 и содержали от 58 до $65 \% \mathrm{CaO}$ (табл. 1 ).

Содержание свободной извести в клинкерах приведено в табл. 2 (определение производилось этилово-глицератным методом). Полученные данные показали, что свободная известь присутствует в значительном количестве в клинкерах, содержащих более $62 \% \mathrm{CaO}_{\text {общ }}$ (KН более $0,85)$. Испытание этих же цементов на равномерность изменения объема (по методике испытания цементов на малых образцах Ю. М. Бутта ['] показало, что содержание $4 \%$ и более $\mathrm{CaO}_{\text {своб }}$ служит причиной образования трещин на лепешках (табл. 2). В связи с этим увеличение общего содержания $\mathrm{CaO}$ в расплаве может привести к получению из него цемента, не обладающего равномерностью изменения объема.

С другой стороны, испытание механических свойств плавленых цементов, полученных в лабораторных условиях, показало (табл. 2), что прочность-на сжатие цементов тем больше, чем выше содержание в них

* Экспериментальная часть работы выполнена при участии старшего инженера И. А. Рожновой. 
окиси кальция. Следовательно, для получения наилучших плавленых цементов необходимо найти пути, позволяющие получить из высокоизвестковых сланцезольных расплавов клинкеры, не содержащие значительных количеств $\mathrm{CaO}_{\text {своб }}$.

Таблица 1

Химический состав плавленых клинкеров (\%)

\begin{tabular}{|c|c|c|c|c|c|c|}
\hline $\begin{array}{l}\text { № клинкера } \\
\text { Компо- } \\
\text { ненты }\end{array}$ & 105 & 104 & 103 & 102 & 101 & 107 \\
\hline $\begin{array}{l}\mathrm{SiO}_{2} \\
\mathrm{Al}_{2} \mathrm{O}_{3} \\
\mathrm{Fe}_{2} \mathrm{O}_{3} \\
\mathrm{FeO} \\
\mathrm{CaO} \\
\mathrm{MgO} \\
\mathrm{Na} \mathrm{N}_{2} \mathrm{O}+\mathrm{K}_{2} \mathrm{O} \\
\mathrm{FeS} \\
\mathrm{SO}_{3} \\
\mathrm{CO}_{2}\end{array}$ & $\begin{array}{r}24,60 \\
6,56 \\
1,59 \\
1,98 \\
58,15 \\
4,24 \\
0,90 \\
2,19 \\
0,23 \\
0,18\end{array}$ & $\begin{array}{r}24,06 \\
5,73 \\
1,36 \\
2,33 \\
58,37 \\
4,36 \\
0,91 \\
1,86 \\
0,23 \\
0,32\end{array}$ & $\begin{array}{r}21,65 \\
5,63 \\
1,07 \\
1,94 \\
61,96 \\
4,15 \\
0,99 \\
1,84 \\
0,22 \\
0,30\end{array}$ & $\begin{array}{r}21,25 \\
6,31 \\
0,60 \\
1,72 \\
62,62 \\
4,16 \\
0,96 \\
2,45 \\
0,24 \\
0,26\end{array}$ & $\begin{array}{r}20,00 \\
4,84 \\
1,01 \\
0,61 \\
64,76 \\
4,64 \\
1,16 \\
2,08 \\
0,16 \\
0,34\end{array}$ & $\begin{array}{r}18,50 \\
4,51 \\
0,81 \\
1,44 \\
65,18 \\
4,71 \\
1,12 \\
1,84 \\
0,17 \\
0,61\end{array}$ \\
\hline И тоro & 100,62 & 99,53 & 99,75 & 100,57 & 99,60 & 98,89 \\
\hline KH & 0,68 & 0,72 & 0,86 & 0,87 & 1,01 & 1,11 \\
\hline
\end{tabular}

П р и меч а н и е. Химические анализы выполнены старшим инженером C. Мармор.

Кристаллизация огненножидких силикатных расплавов происходит при быстром охлаждении их в неравновесных условиях, причем в конечном продукте охлаждения могут присутствовать метастабильные фазы, выделившиеся при высоких температурах из расплава и не успевшие при дальнейшем охлаждении раствориться. Изучение диаграммы плавкости системы $\mathrm{CaO}-\mathrm{Al}_{2} \mathrm{O}_{3}-\mathrm{SiO}_{2}$ показывает, что кристаллизация всех трехкомпонентных расплавов, содержащих более $68 \% \mathrm{CaO}$, начинается с выделения свободной извести. В портланд-цементных расплавах, содержащих кроме $\mathrm{CaO}, \mathrm{Al}_{2} \mathrm{O}_{3}$ и. $\mathrm{SiO}_{2}$ еще около $10 \%$ других окислов ( $\mathrm{Fe}_{2} \mathrm{O}_{3}, \mathrm{R}_{2} \mathrm{O}$ и т. д.), выделение $\mathrm{CaO}$ в качестве первичной фазы должно начинаться, соответственно, при содержании в расплаве около $61 \%$ $\mathrm{CaO}_{\text {общ }}(\mathrm{KH}>0,8)$.

Однако, из расплавов, содержащих от 61 до $64-65 \% \mathrm{CaO}$ (KH от 0,8 до 1,0), известь выделяется только в качестве неравновесной фазы, т. е. образовавшиеся при медленном охлаждении этих расплавов кристаллы $\mathrm{CaO}$ должны снова раствориться (резорбция СаO). Присутствие в конечном продукте кристаллизации расплавов 102 и 101 (КН 0,87 и 1,01 ) значительных количеств свободной извести (табл. 2) свидетельствует о том, что при охлаждении этих расплавов равновесие не было достигнуто.

Из диаграммы плавкости $\mathrm{CaO}-\mathrm{Al}_{2} \mathrm{O}_{3}-\mathrm{SiO}_{2}$ следует также, что максимальное количество окиси кальция, способной выделиться из расплава в качестве неравновесной фазы (при нахождении фигуративной точки жидкой фазы на тройной диаграмме на пограничной линии между полями первичной кристаллизации $\mathrm{CaO}$ и $\left.2 \mathrm{CaO} \cdot \mathrm{SiO}_{2}\right)$, тем больше, чем выше общее содержание $\mathrm{CaO}$ в расплаве. Так,

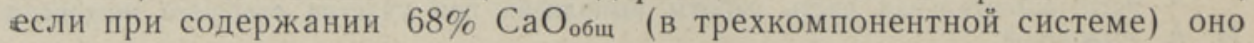




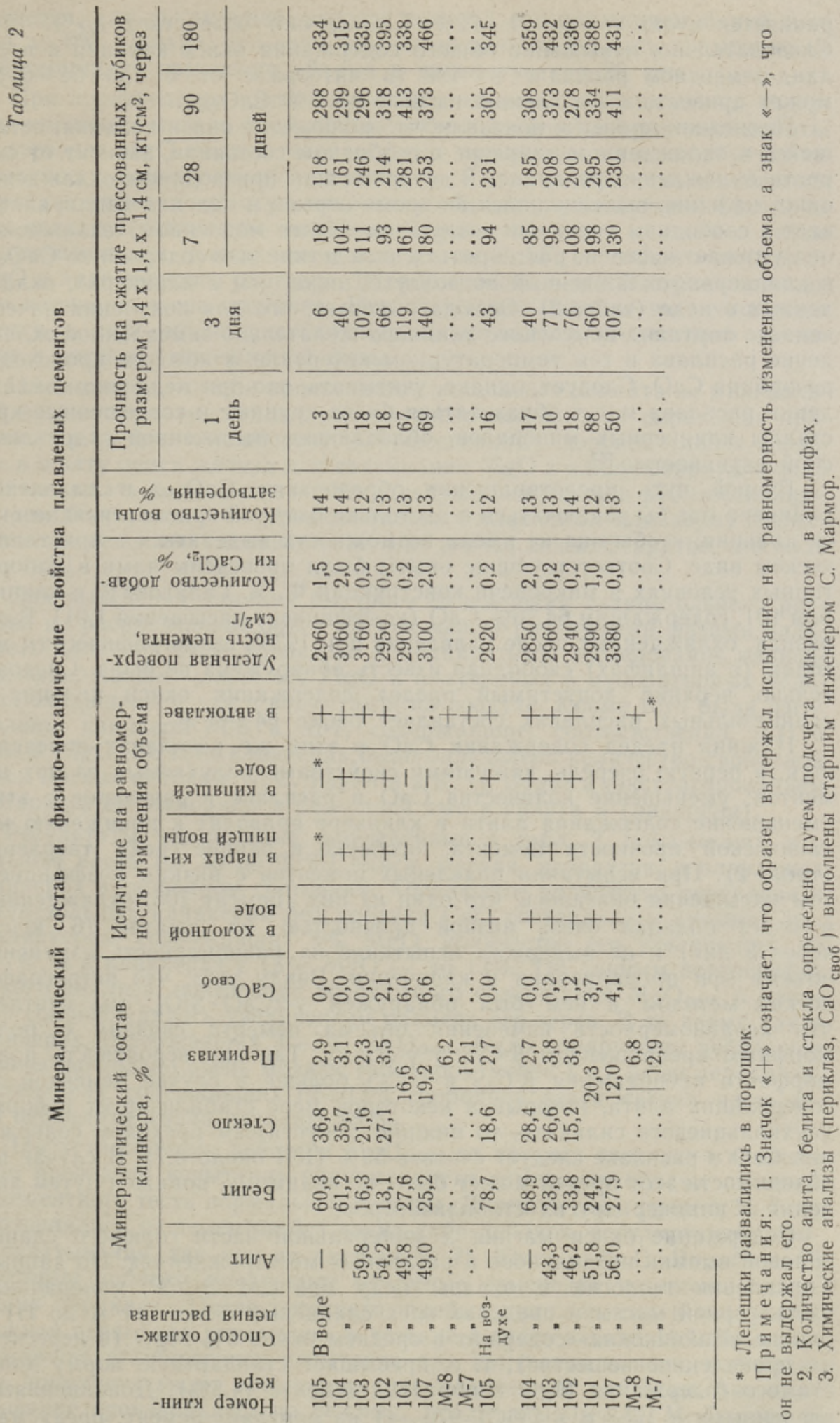


равняется нулю, то при $71-72 \% \mathrm{CaO}_{\text {общ }}$ оно возрастает до $9-12 \%$. Следовательно, повышение общего содержания окиси кальция в портланд-цементном расплаве на $1 \%$ (в интервале от 61 до $64-65 \%$ ) может привести к выделению из него до $3 \%$ СаО своб.

Проведенные опыты показали, что количество окиси кальция, оставшейся в охлажденном клинкере в свободном состоянии, зависит от скорости охлаждения расплава. В то время как при водяном охлаждении окись кальция, выделившаяся во время отрыва и падения капли, застывает в свободном виде, при воздушном (более медленном) охлаждении она успевает частично раствориться, вследствие чего содержание $\mathrm{CaO}_{\text {сво }}$ в клинкерах, охлажденных на воздухе, ниже, чем в клинкерах, охлажденных в воде (табл. 2). Отсюда вытекает, что для получения качественного портланд-цементного клинкера желательно замедленное охлаждение расплава в том температурном интервале, в котором происходит резорбция $\mathrm{CaO}$. Следует, однако, учитывать, что при медленном охлаждении расплава могут образоваться более крупные и совершенные кристаллы клинкерных минералов, обладающие пониженной гидравлической активностью [5].

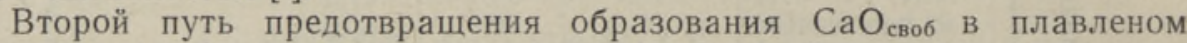
клинкере мог бы заключаться в настолько быстрой кристаллизации окиси кальция, чтобы она не имела возможности выделиться в кристаллическом виде, Соответствующие опыты были проведены нами в лабораторных условиях в микропечи конструкции $Ф$. Я. Галахова $\left[{ }^{2}\right]$ с клинкером 101, содержащим 64,76\% $\mathrm{CaO}$ (коэффициент насыщения 1,01 ). В образцах, охлажденных после плавления при $1930^{\circ}$, петрографическим методом (в аншлифах) свободная известь обнаружена не была. Следовательно, верхний допустимый предел содержания окиси кальция в сланцезольных расплавах составляет около $64-65 \%$.

Нижний предел содержания $\mathrm{CaO}$ в этих же расплавах определяется, в первую очередь, вяжущими свойствами получаемых из них цементов: уменьшение количества $\mathrm{CaO}$ в расплаве и связанное с этим уменьшение содержания алита в клинкере приводит к понижению механической прочности цемента, особенно в ранние сроки твердения (табл. 2). При испытании плавленых цементов с низким коэффициентом насыщения оказалось, что один из них (цемент 105, охлажденный в воде) обладал очень низкой прочностью на сжатие $\left(6 \mathrm{kr} / \mathrm{cm}^{2}\right.$ через 3 дня) и не выдержал испытание на равномерность изменения объема при пропаривании и кипячении. Ввиду того, что петрографическим методом в нем был обнаружен $\gamma-2 \mathrm{CaO} \cdot \mathrm{SiO}_{2}$, мы считаем, что неравномерность изменения объема цемеңта связана с полиморфным превращением $\beta-\mathrm{C}_{2} \mathrm{~S}$ в $\gamma$-форму. Так как вероятность полиморфного превращения $\beta-\mathrm{C}_{2} \mathrm{~S}$ в $\gamma-\mathrm{C}_{2} \mathrm{~S}$ больше в случае цементов, не содержащих алита, который в некоторой мере стабилизирует $\beta$-форму двухкальциевого силиката, то нижним допустимым пределом содержания $\mathrm{CaO}$ в расплаве следует считать $59 \%$ (KН около 0,7$)$. В случае необходимости этот предел может быть, по-видимому, понижен путем введения в клинкер других стабилизаторов.

Содержание окиси магния в минеральной части горючего сланца валовой выемки неодинаково в различных месторождениях. По данным Управления геологии и охраны недр при СМ ЭССР, минеральная часть горной массы в пределах всех сланцевых слоев (от А до Н) в районе «Вийвиконна» содержит в среднем около $5 \%$ MgO (в пересчете на прокаленное вешество), т. е. превышает стандартную норму допустимого содержания $\mathrm{MgO}$ в портланд-цементе $(4,5 \%)$. Дополнениями, введенными в 1958 г. в ГОСТ $970-41$ на портланд-цемент, предусмат- 
ривается, как исключение, выпуск цемента с содержанием окиси магния до $6 \%$. Однако, при этом цемент должен выдержать испытание на равномерность изменения объема в автоклаве при 20 атм.

При производстве портланд-цемента из сырья с повышенным содержанием окиси магния необходимо технологическими приемами добиться перевода $\mathrm{MgO}$ в такие твердые фазы, которые не вызывали бы неравномерности изменения объема цемента. При производстве спекшегося портланд-цемента это осуществляется обычно двумя путями. Одним из них является увеличение содержания окиси железа в цементе с целью получения в нем повышенного количества $\mathrm{C}_{\mathrm{A}} \mathrm{AF}$, способного связывать $\mathrm{MgO}$ в виде твердого раствора. Второй способ - это быстрое охлаждение клинкера после спекания. При этом окись магния частично выделяется в виде мелкокристаллического периклаза, а частично застывает в составе стекловидной фазы.

Имея в виду, что при производстве плавленого цемента из минеральной части горючего сланца предусмотрена дошихтовка сырья, как правило, только одним компонентом (известняком), дополнительное введение в шихту окиси железа для связывания $\mathrm{MgO}$ в алюмоферриты нужно рассматривать только как потенциальную возможность решения вопроса, тем более, что в быстроохлажденных плавленых клинкерах промежуточное вещество застывает часто не в виде алюмоферритов, а в виде стекла [3].

Для выяснения влияния быстрого охлаждения сланцезольного расплава на распределение окиси магния между различными фазами плавленого клинкера было проведено дополнительное исследование клинкеров, содержавших около $4 \% \mathrm{MgO}$ и полученных в лабораторных условиях охлаждением как в воде, так и на воздухе. Кроме того были изготовлены клинкеры M-8 и M-7, содержавшие, соответственно, 8,31 и $14,68 \% \mathrm{MgO}$. Во всех клинкерах было определено количество свободной окиси магния методом W. C. Taylor'a и R. H. Bogue'a (экстрагированием азотнокислым аммонием в безводной смеси спирта и глицерина).

Результаты определения, приведенные в табл. 2, показывают, что бо́льшая часть (от 50 до $90 \%$ ) окиси магния нахөдится в плавленых клинкерах в свободном состоянии. Абсолютное количество периклаза в сланцезольных клинкерах без добавки $\mathrm{CaO}$ составляло в среднем $3 \%$, -в клинкерах, содержавших $8 \% \mathrm{MgO}$, количество его увеличилось до 6 -7\%, а в клинкерах с $15 \%$ MgO - до $13 \%$. По данным петрографи-

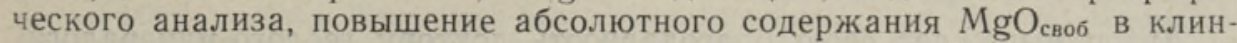
кере сопровождалось увеличением размера его зерен. В то время как в клинкерах, содержавших 3-7\% $\mathrm{MgO}_{\text {своб }}$, было обнаружено небольшое количество только очень мелких (размером менее $1 \mu$ ) зерен периклаза, в клинкерах, содержавших 12-13\% свободной окиси магния, часть зерен периклаза имела размеры до $5 \mu$.

Для установления действия $\mathrm{MgO}_{\text {своб }}$ на процесс твердения цемента было проведено испытание равномерности изменения объема лепешек из цементного теста нормальной густоты. Лепешки диаметром в $3-4$ см изготовлялись из цементов без каких-либо добавок, регулирующих сроки схватывания, так как по данным В. Н. Юнга и Х. С. Воробьева $\left.{ }^{6}\right]$ некоторые добавки уменьшают объемные изменения цементов, содержащих периклаз. После суточного пребывания лепешек в воздушновлажной среде, они кипятились в течение 4 часов в воде. Цементы, выдержавшие обыкновенное испытание при кипячении в воде, подвергались дополнительному испытанию при повышенном давлении. Автоклавирование производилось по режиму, предложенному С. М. Рояком и 
В. В. Мышляевой [4]: давление повышалось в течение 3,5 часа, выдержка при 20 атм длилась 3 часа, спуск давления - 2 часа. Проведенные опыты показали (табл. 2), что лепешки из плавленых цементов, содер-

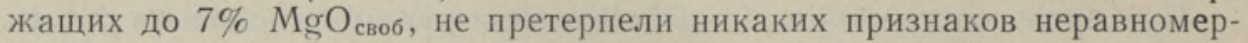
ного изменения объема, и только часть тех лепешек, которые содержали $12-13 \% \mathrm{MgO}_{\text {сво6 }}$, развалилась в порошок.

На основе проведенных исследований можно сказать, что обшее содержание $\mathrm{MgO}$ в плавленых клинкерах в количестве, по крайней мере, до $6 \%$ не ухудшает качество цемента, так как большая часть ее находится в быстроохлажденных плавленых клинкерах в виде мелкокристаллического периклаза, гидратирующегося одновременно с клинкерными минералами.

\section{Выводы}

1. Содержание свободной извести в плавленых клинкерах с коэффициентом насыщения выше 0,8 зависит от режима охлаждения расплава.

2. Имеется возможность получить плавленые клинкеры с коэффициентом насыщения по крайней мере до 1,0, выдерживающие испытание на равномерность изменения объема при нормальном давлении, либо путем очень быстрой закалки огненножидкого расплава, либо путем замедленного охлаждения его в интервале резорбции для растворения той окиси кальция, которая выделяется из расплава в начале кристаллизации. В связи с этим верхний допустимый предел содержания $\mathrm{CaO}$ в сланцезольных расплавах составляет около $64-65 \%$.

3. Плавленые цементы, не содержащие трехкальциевого силиката, характеризуются замедленным повышением механической прочности. Кроме того, имеющийся в их составе $\beta-2 \mathrm{CaO} \cdot \mathrm{SiO}_{2}$ склонен к переходу в $\gamma$-форму, ввиду чего нежелательно понижение содержания СаO в сланцезольном расплаве ниже $59 \%$ ( $\mathrm{KH} \approx 0,7)$.

4. Окись магния находится в плавленых клинкерах, полученных путем быстрого охлаждения сланцезольных расплавов, в основном в свободном состоянии в виде мелкокристаллического периклаза.

5. Содержание окиси магния в быстроохлажденных плавленых клинкерах может быть повышено до $6 \%$ без ухудшения качества цемента из-за неравномерности изменения объема.

Автор выражает свою благодарность доктору геолого-минералогических наук профессору Н. Л. Дилакторскому, под руководством которого выполнена настоящая работа.

\section{Л И Т Е Р А У Р А}

1. Ю. М. Бутт, Практикум по технологии вяжущих веществ и изделий из него, М., Промстройиздат, ' 1953.

2. Ф. Я. Гал ахов, Высокотемпературная микропечь для изучения гетерогенных равновесий в системах тугоплавких силикатов, Сб. Современные методы нсследования силикатов и строительных материалов, Госстройиздат, 1960.

3. Н. Л. Дил акто рски й и $M$. К и й ле $\mathrm{p}$, Плавленый портланд-цемент из минеральной части горючего сланца, Изв. АН ЭССР. Серия техн. и физ.-мат. наук, т. IX, № 1, 1960.

4. С. М. Р ояк, В. В. Мышля е ва, Об автоклавном испытании магнезиальных цементов, Сб. Памяти В. В. Серова, 1957.

5. П. Ф. Румянцев, Н. А. Торопов, Активизация вяжущих свойств доменных шлаков, Тр. Ленингр. технол. ин-та им. Ленсовета, вып. 41, 1957. 
6. В. Н. Юн г, Х. С. В оробьев, О получении портланд-цемента с высоким содержанием окиси магния, Тр. Моск. хим.-технол. ин-та им. Д. И. Менделеева, № $24,1957$.
Институт строительства и строительных материалов Академии наук Эстонской ССР
Поступила в редакцию
5. VII 1960

\title{
LUBATUD CaO- JA MgO-SISALDUSE PIIRID SULATATUD PORTLANDTSEMENDI KLINKRIS
}

\author{
M. Kiiler, \\ tehniliste teaduste kandidaat
}

Resümee

Uuriti mitmesuguse $\mathrm{CaO}$ - ja $\mathrm{MgO}$-sisaldusega portlandtsemente, mis saadi laboratoorsel teel pōlevkivi (koos lubjakivi vahekihtidega) mineraalosa sulatamisel atsetüleeni ja hapniku leegis.

Katsed näitasid, et ühtlase mahumuutusega, sulatatud portlandtsemendi saamine on vōimalik ka $64-65 \% \mathrm{CaO}$-sisaldusega sulamitest (küllastuskoefitsient $\mathrm{KH} \sim 1$ ), kui neid jahutada nii, et vaba kaltsiumoksüüd kas ei jõuaks sulamist välja kristalluda, vōi, kui ta siiski eraldub, jōuaks lahustuda enne sulami lōplikku hangumist. Mittesobiva jahutusrežiimi puhul võib vaba lubi esineda suurtes kogustes isegi klinkrites, mille üldine $\mathrm{CaO}$ sisaldus on suhteliselt madal $(\mathrm{KH} \sim 0,85)$, pōhjustades nende tsementide mitteühtlasi mahumuutusi. Eriti väikese kaltsiumoksüüdisisaldusega klinkrites $(\mathrm{KH} \sim 0,7)$, kui neis puudub $3 \mathrm{CaO} \cdot \mathrm{SiO}_{2}$, võib esineda $\beta-2 \mathrm{CaO} \cdot \mathrm{SiO}_{2}$ üleminek $\gamma$-vormi, mis pōhjustab tsemendi mehaanilise tugevuse tunduva languse. Seetōttu on $\mathrm{CaO}$-sisalduse lubatud alampiir pōlevkivituha sulamites $59 \%$ lähedal.

Magneesiumoksüüd esineb sulatatud portlandtsemendi klinkrites peamiselt sidumata kujul isegi küllalt kiire jahutuse korral, kuid kristallide peensuse tōttu ta ei kutsu esile mahumuutusi (katsed ka 20 atm rōhu juures) sulatatud tsementides, mille üldine $\mathrm{MgO}$ sisaldus on kuni $6 \%$.

Eesti NSV Teaduste Akadeemia

Ehituse ja Ehitusmaterjalide Instituut
Saabus toimetusse

5. VII 1960

\section{DIE GRENZEN DES ZULÄSSIGEN CaO- UND MgO-GEHALTS IM KLINKER DES GESCHMOLZENEN PORTLANDZEMENTS}

M. Kiiler

\section{Zusammenfassung}

Es wurden Portlandzemente von verschiedenem $\mathrm{CaO}$ - und $\mathrm{MgO}$-Gehalt untersucht, die auf laboratorischem Wege durch Schmelzung des mineralischen Teils des Brennschiefers (zusammen mit den Kalkstein-Zwischenschichten) in der Azetylen- und SauerstoffFlamme erhalten wurden.

Die Versuche zeigten, dass es möglich ist, geschmolzenen Portlandzement von einer gleichmässigen Raumänderung auch aus Schmelzen mit $64-65 \% \mathrm{CaO}$-Gehalt (Sättigungsbeiwert $\mathrm{KH} \sim 1$ ), zu bekommen, falls sie derart abgekühlt werden, dass das freie Kalziumoxyd nicht die Zeit hat, sich zu kristallisieren, oder aber, wenn es sich doch absondert, vor dem endgültigen Erstarren der Schmelze wieder aufgelöst wird. Ist das Abkühlungsregime nicht geeignet, so kann freier Kalk in beträchtlichen Mengen sogar in den Klinkern vorkommen, deren allgemeiner $\mathrm{CaO}$-Gehalt verhältnismässig niedrig ist $(\mathrm{KH} \sim 0,85)$. Das hat eine ungleichmässige Raumänderung dieser Zemente zur Folge. Beí Klinkern von besonders geringem Kalziumoxydgehalt (KH $\sim 0,7)$, falls sie kein $3 \mathrm{CaO} \cdot \mathrm{SiO}_{2}$ enthalten, kann $\beta-2 \mathrm{CaO} \cdot \mathrm{SiO}_{2}$ in die $\gamma$-Form übergehen, wodurch die mechanische Festigkeit des Zements bedeutend herabgesetzt wird. Infolgedessen liegt die untereGrenze des zulässigen $\mathrm{CaO}$-Gehalts in der Brennschiefer-Ascheschmelze bei $59 \%$.

Magnesia kommt in Klinkern des geschmolzenen Portlandzements vornehmlich ungebunden vor, und zwar auch bei ausreichend rascher Abkühlung; die Feinheit der Kristalle lässt aber in Schmelzzementen, deren allgemeiner MgO-Gehalt nicht über 6\% ist, keine Raumänderungen entstehen (Versuche auch bei einem Druck von 20 atm).

Institut für Bauwesen und Baumaterialien der Akademie der Wissenschaften der Estnischen SSR
Eingegangen am 5. Juli 1960 